\title{
PERANAN KEPOLISIAN DALAM PENANGGULANGAN AKSI UNJUK RASA ANARKIS DI WILAYAH HUKUM KEPOLISIAN DAERAH SULAWESI SELATAN DAN BARAT
}

\author{
THE POLICE'S ROLE TO HANDLE THE ANARCHISTIC \\ DEMONSTRATOR IN JURISDICTION OF REGIONAL POLICE OF \\ SOUTH AND WEST SULAWESI
}

\author{
1.Fadli Yasser Arafat Juanda, ${ }^{2}$ Asrullah ${ }^{3}$ Andi dewi Pratiwi \\ fadly.yasser@gmail.com \\ ${ }^{1}$ Bagian Hukum Pidana Universitas Sulawesi Barat \\ (email:fadly.yasser@gmail.com) \\ ${ }^{2}$ Bagian Hukum Pidana Universitas Sulawesi Barat \\ (email: Asrullah@unsulbar.ac.id) \\ ${ }^{3}$ Bagian Hukum Acara Universitas Sulawesi Barat \\ (email: andidewipratiwii@gmail.com)
}

\begin{abstract}
Abstrak
Penanganan aksi unjuk rasa oleh kepolisian di wilayah hukum sulselbar menunjukkan bahwa masih dapat diatasi dengan melakukan tindakan pre-emtif, prefentif dan represif. Penelitian ini bertujuan untuk mengkaji faktorfaktor yang menyebabkan maraknya aksi unjuk rasa anarkis dan peran kepolisian dalam upaya penanggulangan aksi unjuk rasa anarkis di wilayah Kepolisian Daerah Sulawesi Selatan dan Barat. Penelitian ini dilakukan di Kepolisian Daerah Sulawesi Selatan dan Barat, Kepolisian Resort Kota Besar Makassar, Kepolisian Resort Gowa, Kepolisian Resort Maros, Pemerintah Kota Makassar, Pemerintah Daerah Gowa, Pemerintah Daerah Maros dan Dewan Perwakilan Rakyat Daerah Sulawesi Selatan. Penelitian ini adalah penelitian empiris dengan mengkaji dan menganalisis bekerjanya hukum di dalam masyarakat. Pengumpulan data dilakukan melalui wawancara langsung dengan pihak-pihak yang berkompeten. Hasil penelitian menunjukkan bahwa faktor-faktor yang mengakibatkan maraknya aksi unjuk rasa anarkis adalah rendahnya pengetahuan hukum pengunjuk rasa, adanya kepentingan-kepentingan dari seseorang/kelompok demi memperoleh keuntungan tertentu, dan adanya keyakinan bersama yang muncul dari suatu solidaritas untuk melakukan tindakan-tindakan anarkis saat melakukan unjuk rasa. Peran Kepolisian Daerah Sulawesi Selatan dan Barat dalam melakukan penanggulangan aksi unjuk rasa anarkis dilakukan dengan berbagai upaya baik yang bersifat pre-emtif, preventif dan represif. Upaya pre-emtif dilakukan dengan melakukan pengumpulan informasi, memberikan arahan dan bimbingan serta melakukan dialog interaktif melalui media. Upaya preventif dilakukan dengan mengawal pengunjuk rasa, menjaga objek vital yang menjadi sasaran, mengantisipasi adanya provokator dan memfasilitasi pengunjuk rasa. Upaya represif dilakukan dengan menyiapkan pasukan huru hara, menghambat penyaluran logistik berupa senjata tajam, mengumpulkan alat bukti dan melakukan penyidikan serta menyiapkan sistem pengamanan kota.
\end{abstract}

Kata Kunci : Peran Kepolisian, Unjuk Rasa, Anarkis

\begin{abstract}
Handling rallies by the police in jurisdiction sulserbar shows that they can be addressed by conducting preemptive, preventive, and repressive. This research aims to analyze factors causing the increasing anarchistic demonstration and the efforts of the police to overcome the anarchistic demonstration in jurisdiction of South and West Sulawesi. This research was conducted in the police jurisdiction in South and West Sulawesi, the Police Resort of: Makassar, Gowa, and Maros, Government of: Makassar City, Gowa Regency, Maros Regency and Regional People's Representative Council of South Sulawesi. This empirical research was conducted
\end{abstract}


through direct interview with the competent parties. The results indicate that factors causing the increase of anarchistic demonstration are the lack of knowledge of law of demonstrators, there are interests of someone/groups to get certain benefits, and they have common believes emerge from solidarity to do anarchistic action during demonstration. The Role of The Regional Police of South and West Sulawesi to cope the anarchistic demonstrations, they take measures such as pre-emptive, preventive, and repressive. The efforts of pre-emptive are the collect information for guiding and to make interactive dialogue through media, the preventive efforts are to escort the demonstrators, to guard the targeted vital objects, to anticipate provokers and to facilitate the demonstrators. The repressive effort are to prepare riot troops, to hamper the logistic distribution such as sharp weapons, to collect evidence and to perform investigation and to prepare the city pacification system.

Keyword: The Police Role, Demonstration, Anarchy

\section{PENDAHULUAN}

Undang-Undang Dasar memberikan perlindungan kepada setiap warga negara berhak untuk mengemukakan pendapat sebagaimana yang dirumuskan di dalam Pasal 28 UUD 1945, yang bunyi rumusannya adalah "Kemerdekaan berserikat dan berkumpul mengeluarkan pikiran dengan lisan dan tulisan dan sebagainya ditetapkan dengan undang-undang”.

Aksi unjuk rasa yang berujung anarkis akhir-akhir ini sering terjadi di kota kota besar seperti di kota Makassar yang akhir tahun ini saja mendapat perhatian besar karena diberitakan di media nasional baik cetak maupun elektronik. Belum hilang dari ingatan kita bagaimana aksi unjuk rasa yang dilakukan mahasiswa di kota Makassar untuk menolak kenaikan BBM yang merupakan kebijakan dari pemerintahan baru yang dipimpin oleh Jokowi dan Jusuf Kalla, yang berlangsung hingga beberapa hari dengan menutup jalan dan melakukan pembakaran ban yang mengakibatkan kemacetan panjang yang terjadi di sejumlah jalan di kota Makassar yang mengakibatkan kerugian materi maupun nonmateri.

Dalam mengamankan unjuk rasa dari tindakan yang melanggar hukumtersebut, upaya Kepolisian Negara Republik Indonesia (Polri) dan masyarakat di tanah air sangatlah penting demi menjaga ketentraman Bangsa dan Negara Indonesia. Dengan dikeluarkannya UndangUndangNomor 9 Tahun 1998 tanggal 16 Oktober 1998 tentang “Kemerdekan Menyampaikan 
Pendapat di Muka Umum", maka Polri diharapkan mampu menangani semaraknya unjuk rasa atau demonstrasi dewasa ini.

Kasus Unjuk Rasa akhir-akhir ini yang terjadi di kota Makassar yang tidak tertangani dengan baik, hal ini tentu saja akan menimbulkan kekacauan yang pada akhirnya mengakibatkan kerugian dan menimbulkan korban baik berupa korban jiwadan korban harta benda bahkan aktivitas transportasi dan ekonomi menjadi terhambat dikarenakan unjuk rasa yang bersifat anarkis tersebut. Namun tentunya pihak Kepolisian Negara RI tidak tinggal diam dalam mengantisipasi keadaan tersebut.

Pihak Polri telah melakukan upaya baik dalam tataran pembenahan instrument maupun dalam tatanan operasional untuk meredam keganasan unjuk rasa yang bersifat anarkis tersebut. Hingga terakhir yaitu Tahun 2010 Polri mengeluarkan peraturanyaitu Prosedurtetap Kapolri No: Protap 1/x/ Tahun 2010 tentang "Pedoman Penanggulangan anarki”. Peraturan Kapolri tersebut tentunya telah berjalan sampai sekarang ini sehingga dalam pelaksanaannya pastilah masih terdapat kekurangan disana sini, walaupun diakui secara substansial peraturan kapolri tentang pedoman penanggulangan anarki tersebut merupakan produk/instrument yang paling terbaru dan sudah banyak mengatur bagaimana setiap satuan fungsional Polri untuk bertindak dalam meredam unjuk rasa. Adapun tujuan dari penelitian ini yaitu untuk mengetahui faktor yang menyebabkan maraknya aksi unjuk rasa anarkis.

\section{METODE PENELITIAN}

\section{Lokasi Penelitian}

Penelitianini dilakukan di wilayah Kepolisian Daerah Sulawesi Selatan dan Barat akan dilakukan di Kepolisian Daerah Sulawesi Selatan,Kantor Polrestabes Makassar, Kantor Polres Gowa, Kantor Polres Maros, Pemerintah kota Makassar, Pemda Maros, Pemda Gowa dan kantor DPRD Provinsi. Jenis penelitian ini adalah penelitian hukum empiris.

\section{Populasi dan Sampel}

Populasi dalam penelitian ini adalah aparat Kepolisian, Mahasiswa, LSM, Buruh, Akademisi, Aparat Pemerintah kota/daerah, Tokoh Masyarakat dan Anggota DPRD Provinsi. Sedangkan sampel dalam penelitian ini adalah Aparat Kepolisian berjumlah 6 Orang, Aparat Pemkot/Pemda berjumlah 3 Orang, Anggota DPRD berjumlah3 Orang, Akademisi berjumlah 3 Orang, Tokoh Masyarakat berjumlah 2 Orang, Mahasiswa 13 Orang, LSM/Ormas berjumlah 3 Orang dan Buruh berjumlah 4 Orang.

\section{Teknik Pengumpulan Data}

Untuk memperoleh data yang diperlukan, maka digunakan teknik Pengumpulan data 
melalui Interview (wawancara), yaitu dilakukan dengan cara diskusi dan Tanya jawab dengan pihak yang kompeten terkait isu yang dibahas dalam tesis ini (Marzuki, 2013).

\section{Analisis Data}

Data yang diperoleh dilapanganbaik secara primer maupun sekunder dianalisis secara deskriptif dengan teknik kualitatif,yaitu dengan menggambarkan, menguraikan dan menjelaskan masalah-masalah yang akan dalam penelitian ini.

\section{HASIL PENELITIAN}

Hasil penelitian menunjukan bahwa Pengetahuan hukum merupakan unsur penting dari dipatuhinya atau ditegakkannya suatu aturan, bagaimana mungkin melaksanakan suatu aturan jika aturan tersebut tidak diketahui baik keberadaannya maupun isi dari aturan tersebut. Sebagian besar pengunjuk rasa dari dari kelompok aliansi mahasiswa belum mengetahui mengenai keberadaan suatu undang-undang yang mengatur tentang cara atau prosedur pelaksanaan aksi unjuk rasa yang diatur dalam Undang-undang Nomor 9 tahun 1998 tentang Kemerdekaan Menyampaikan Pendapat di Muka Umum.

Ketidaktahuan pengunjuk rasa yang terkait prosedur atau ketentuan yang berdasarkan pada ketentuan peraturan perundang-undangan yang ada mengakibatkan seringkali terjadinya tindakan-tindakan yang mengarah kepada suatu tindakan yang anarkis yang dapat merugikan orang lain secara langsung maupun tidak langsung. Secara langsung misalnya akibat tindakan tersebut mengakibatkan orang lain menderita luka baik ringan maupun luka berat, sedangkan dampak tidak langsung yang timbul ialah aksi tersebut mengakibatkan terjadinya kemacetan yang merugikan secara ekonomi. Kemudian Faktor ekonomi atau kesejahteraan menjadi salah satu faktor yang dapat berpengaruh terhadap suatu aksi unjuk rasa anarkis khususnya di wilayah Polda Sulselbar.

Unjuk rasa yang anarkis berdampak pada ketidakpuasan warga masyarakat khususnya para pelaku ekonomi yang aktivitasnya merasa terganggu dan merugikan mereka. Sehingga mereka menuntut, kepada pihak mahasiswa dan maupun pihak keamanan untuk mengambil tindakan tegas agar para pengunjuk rasa menyadari pentingnya memperhitungkan kepentingan warga masyarakat yang terganggu aktivitas ekonominya. Selain itu Faktor lingkungan atau pergaulan menjadi salah satu faktor yang mempengaruhi suatu aksi unjuk rasa sehingga berujung dengan tindakan anarkis.

Dalam menjalankan tugas dan fungsi kepolisian khususnya dalam penanggulangan 
aksi unjuk rasa yang anarkis, kepolisian senantiasa melaksanakan koordinasi antara Kepolisian daerah (Polda) tingkat Provinsi, dengan Kepolisian Resort (Polres) di tingkat Kabupaten/kota. Dalam melakukan pengamanan unjuk rasa di suatu tempat dalam wilayah kota, maka yang bertugas melakukan pengamanan ialah Polres setempat, apabila unjuk rasa berjalan eskalasi atau gangguan yang besar dan tidak bisa lagi dikendalikan oleh Polres, maka Polres akan meminta bantuan kepada Polda untuk membantu penanggulangan tindakan anarkis dalam unjuk rasa.

Setiap pelaksanaan tugas penanganan unjuk rasa yang dilakukan oleh Polrest dibawah komando Polda, harus mengacu kepada urut-urutan ataupun prosedur pelaksanaan tugas yang telah ditetapkan. Prosedur ini menjadi acuan bagi setiap personel Polres karena memuat tahapan yang sistematis agar tujuan serta sasaran yang telah ditetapkan dapat tercapai dengan hasil yang baik.

Prosedur yang dilakukan oleh Sat sabhara tiap-tiap Polres dalam menanggulangi aksi unjuk rasa ini didasarkan pada Peraturan Kapolri Nomor 16 Tahun 2006 tentang Pedoman Pengendalian Massa dan Perkap Nomor 1 Tahun 2010. Adapun dalam pelaksanaan mengamankan aksi unjuk rasa oleh Satuan sabhara Polres dapat dilihat melalui tiga bagian, yaitu persiapan, pelaksanaan di lapangan, dan tahap setelah pelaksanaan tugas.

\section{PEMBAHASAN}

Hasil penelitian menemukan bahwa faktor yang menyebabkan maraknya aksi unjuk rasa adalah faktor pengetahuan hukum.Pengetahuan hukummerupakan unsur penting dari dipatuhinya atau ditegakkannya suatu aturan, bagaimana mungkin melaksanakan suatu aturan jika aturan tersebut tidak diketahui baik keberadaannya maupun isi dari aturan tersebut. Sebagian besar pengunjuk rasa dari dari kelompok aliansi mahasiswa belum mengetahui mengenai keberadaan suatu undang-undang yang mengatur tentang cara atau prosedur pelaksanaan aksi unjuk rasa yang diatur dalam Undang-undang Nomor 9 tahun 1998 tentang Kemerdekaan Menyampaikan Pendapat di Muka Umum.

Demonstrasikadang diartikan sempit sebagai long-march, berteriak-teriak, membakar ban, dan aksi teatrikal. Pilippe C. Schmitter dan TerryLyn Karl, demokrasi sebagai sistem pemerintahan dimana pemerintah diminta tanggung jawab atas tindakan tindakan mereka diwilayah public oleh warga Negara, yang bertindak secara tidak langsung melalui kompetisi dan kerja sama dengan para wakil mereka yang telah dipilih(Ma'arif, 2008).

Demokrasi berkaitan erat dengan demonstrasi. Mengutip pendapat Nurcholis Madjid dalam Muhari yang mengatakan bahwa, nilai demokrasi yang abstrak menjadi lebih aplikatif untuk mempermudah dijabarkan serta diterapkan dalam kehidupan sosia-politik Indonesia sebagai tegaknya demokratisasi di Indonesia (Muhari, 2006). 
Dalam pandangan Gabriel A. Almond bahwa demonstrasi atau aksi unjuk rasa merupakan bentuk partisipasi politik yang non konvensional, yang biasanya digunakan oleh orang untuk mempengaruhi kehidupan politik dan kebijaksanaan pemerintahan bila bentukbentuk aktivitas lain tidak bisa dilakukan atau tampak tidak efektif (Redanaet al., 2001).

Unjuk rasa sebagai HAM merupakan hak asasi manusia yang diperoleh dan dibawanya bersama dengan kelahiran serta kehadirannya dalam kehidupan masyarakat, tanpa membedakan bangsa, ras, agama dan jenis kelamin karena sifatnya yang asasi dan universal(Syarbaini, 2004).

Sebayak Kuta Buluh ditangkap karena menolak penjajahan dengan mengorganisir rakyat untuk berdemonstrasi ke pusat kekuasaan Belanda di Saribu Dolok, menentang penerapan rodi dan belasting. Inilah peristiwa demonstrasi pertama yang ditemukan dalam sejarah Indonesia (peoples power)(Prinst, 2001).

Faktor yang mengakibatkan unjuk rasa adalah bahwa sebagian besar pengunjuk rasa dari dari kelompok aliansi mahasiswa belum mengetahui mengenai keberadaan suatu undangundang yang mengatur tentang cara atau prosedur pelaksanaan aksi unjuk rasa yang diatur dalam Undang-undang Nomor 9 tahun 1998 tentang Kemerdekaan Menyampaikan Pendapat di Muka Umum. Akibatnya kesadaran hokum masyarakat menjadi berkurang. (Soekanto dkk., 
1979).

Faktor berikutnya adalah ekonomi unjuk rasa yang anarkis berdampak pada ketidakpuasan warga masyarakat khususnya para pelaku ekonomi yang aktivitasnya merasa terganggu dan merugikan mereka. Selain itu, faktor lingkungan mengakibatkan munculnya yang disebut perilaku kolektif (collective belief), Perilaku kolektif ini bukanlah semata-mata merupakan perilaku kelompok-kelompok tertentu, akan tetapi juga dilakukan sekelompok orang yang pada umumnya tidak saling mengenal, bersifat spontan dan mudah cair (dalam arti menghentikan perilakunya(Meliala, 2001).

Pengunjuk rasa menuntut, kepada pihak mahasiswa dan maupun pihak keamanan untuk mengambil tindakan tegas agar para pengunjuk rasa menyadari pentingnya memperhitungkan kepentingan warga masyarakat yang terganggu aktivitas ekonominnya. Terakhir adalah faktor lingkungan/pergaulan merupakan salah satu faktor pemicu timbulnya tindakan anarkis bagi para pengunjuk rasa yang dapat merugikan baik para pengunjuk rasa maupun warga masyarakat dan juga pihak pemerintah sebagai pengambil kebijakan.

Polri sebagai aparatur penegak hokum terhadap penanganan unjuk rasa merupakan hal yang esensial karena menurut Achmad Ali, polri sebagai salah satu unsur terbentuknya sistem hokum yang baik di Indonesia(Ali, 2001).

Peran Kepolisian dalam penanganan unjuk rasa yaitu Melalui upaya preventif Disini polisi mulai dari melakukan analisis terhadap kondisi wilayah berikut potensi kerawanan yang terkandung di dalamnya sampai dengan upaya koordinasi segenap pihak dalam rangka mengantisipasi timbulnya kejahatan(Rahardjo, 2002).

Pelaksanaan koordinasi antara Kepolisian daerah (Polda) tingkat Provinsi, dengan Kepolisian Resort (Polres) di tingkat Kabupaten/kota. Bentuk penanganan aksi unjuk rasa anarkis oleh kepolisian daerah sulselbar yaitu dibutuhkan adanya kordinasi yang intensif antara pihak pemerintah daerah dan pihak kepolisian demikian pula sosialisasi aturan yang menyangkut unjuk rasa dalam arti menyampaikan pendapat di muka umum sesuai aturan perundangan yang berlaku, dalam bentuk preventif adalah Kepolisian Daerah Sulawesi Selatan dan Barat dapat melakukan langka-langka pendekatan atau persuasif terhadap pengunjuk rasa agar tindak berujung anarkis dengan senantiasa bekerjasama dengan aparat pemerintah provinsi/daerah/kota(Muhari, 2006).

Peran kepolisian dalam bentuk represif ini dilakukan apabila aksi unjuk rasa yang dilakukan oleh pengunjuk rasa telah terjadi tindakan-tindakan anarkis, yang mengganggu keamanan serta ketertiban. Peran ini dilakukan oleh Negoisator, Brimob, Densus 88, Bimmas, Reskrim, Kasatwil dan Polda Lainnya. 


\section{KESIMPULAN DAN SARAN}

Faktor-faktor yang mempengaruhi maraknya aksi ujuk rasa anarkis di Wilayah Kepolisian Daerah Sulawesi Selatan dan Barat adalah a. Pengetahuan hukum pengunjuk rasa, b. Isu-isu terkait persoalan ekonomi/kesejahteraan, seringkali disikapi dengan tindakantindakan anarkis oleh pengunjuk rasa, c. Adanya seseorang atau kelompok orang yang melakukan aksi unjuk rasa yang memang dirancang dengan tindakan-tindakan anarkis, d. Adanya suatu keyakinan bersama (collective belief) untuk mengedepankan tindakan-tindakan anarkis. Sedangkan peran Kepolisian Daerah Sulawesi Selatan dan Barat dalam menanggulangi aksi unjuk rasa anarkis adalah a. Tindakan Pre-emtif oleh Polda Sul-selbar yaitu dengan melakukan melakukan penyelidikan dan pengumpulan informasi, memberikan arahan bimbingan dan petunjuk kepada pengunjuk rasa dan melakukan dialog interaktif dan himbauan melalui media elektronik/massa. b. Tindakan Preventif oleh Polda Sul-selbar yaitu menjaga dan mengatur arus lalu lintas serta memberikan pengawalan terhadap pengunjuk rasa, c. Tindakan Represif Polda Sul-selbar yaitu Menyiapkan pasukan huru hara (PHH) serta peralatan. Hendaknya Kepolisian Daerah Sulawesi-selatan dan Barat dalam menanggulangi aksi unjuk rasa anarkis senantiasa mengedepankan upaya-upaya persuasif khususnya melalui pendekatan nilai-nilai budaya lokal terhadap pengunjuk rasa.

\section{DAFTAR PUSTAKA}

Ali A.(2012). Menguak Teori Hukum (Legal Theory) dan Teori Peradilan (Judicialprudence) Termasuk Interpretasi Undang-Undang. Legisprudence. Jakarta.

Ma'arif A.S. (2008).Politik Demokrasi Di Indonesia. Jakarta: Gramedia.

Marzuki P. M. (2013). Penelitian Hukum. Jakarta : Kencana Prenada Media Group.

MelialaA.(2001). Perilaku Kolektif dan Tndakan Kepolisian: Perspektif Kepolisian. Jurnal Kriminologi Indonesia Vol. I Nomor III.

Muhari. (2006). Norma Norma Yang Menjadi Pandangan Hidup Demokratis. Surakarta

Prinst D. (2001). Sosialisasi \& Diseminasi Penegakan Hak Asasi Manusia. Bandung.

Rahardjo S. (2002). Polisi Sipil Dalam Perubahan Sosial di Indonesia. Jakarta

Redana B. et.al. (2001). Dalam Demokrasi Kekerasan Disintegrasi. Jakarta

Soekanto S. dkk. (1979). Penegakan Hukum. Jakarta

Syarbaini S. (2004). Sosiologi dan Politik. Bogor 